\title{
ОЦЕНКА ОБЪЕМОВ АГРАРНОГО ПРОИЗВОДСТВА В ЗАВИСИМОСТИ ОТ СТРУКТУРЫ РЕСУРСНЫХ ЗАТРАТ
}

\author{
(c) 2020 Потапов Андрей Павлович \\ кандидат экономических наук, ведущий научный сотрудник \\ Институт аграрных проблем Российской академии наук, Россия, Саратов \\ E-mail:appotapov@mail.ru \\ ORCID: 0000-0002-8327-4060
}

Проведены расчеты структуры ресурсных затрат аграрного производства. С использованием метода построения производственной функции исследована степень влияния изменения объема ресурсных затрат на выпуск продукции. Представлены прогнозы объемов валовой продукции сельского хозяйства в зависимости от структуры затрат на основные производственные ресурсы.

Ключевые слова: ресурсный потенциал, аграрное производство, структура затрат, производственная функция, прогнозирование

Введение. Современное развитие аграрного производства России происходит в условиях ограниченных ресурсных возможностей отрасли, связанных с разной степенью обеспеченности хозяйств производственными ресурсами, с дифференциацией технико-технологического уровня ведения сельского хозяйства по категориям производителей, с высокой зависимостью ресурсного потенциала от импорта его основных элементов. Эффективное аграрное производство может быть построено только на основе рационального использования всех видов ресурсов. В настоящее время актуальными становятся задачи формирования и использования ресурсного потенциала аграрного производства, роста ресурсной обеспеченности производителей, совершенствования структуры ресурсного потенциала и повышения его эффективности.

Эффективность аграрного производства, как одно из направлений повышения производительности и конкурентоспособности отраслей национальной экономики, связана непосредственно с использованием ресурсов, со степенью их вовлеченности в производственный процесс. В значительной степени эффективность зависит от количественного и качественного соотношения ресурсов между собой, от их сбалансированности, что определяется структурой используемых ресурсов и структурой затрат на приобретение необходимых ресурсов. Определение структуры затрат, обеспечивающей повышение выхода продукции с единицы ресурса, становится актуальной задачей системы управ- ления сельскохозяйственным производством.

Отношение ресурсных затрат и производственных показателей характеризуется понятием ресурсоемкости. Она отражает долю всех ресурсов или их отдельных видов в стоимости выпущенной продукции и является, таким образом, показателем эффективности использования ресурсного потенциала.

В качестве методологической основы исследования зависимости производственных и ресурсных параметров любого отраслевого комплекса целесообразно использовать межотраслевой баланс (по другому называемый - таблицы «Затраты-Выпуск»), как систему сведений о взаимодействии отраслей в национальной экономике. Он позволяет оценить структуру ресурсных затрат, так как конечная продукция одних отраслей выступает ресурсом в промежуточном потреблении для других отраслей. Коэффициенты прямых затрат из межотраслевого баланса выступают укрупненными характеристиками ресурсоемкости. Эти коэффициенты позволяют определить прогнозные тенденции изменения расхода ресурсов под воздействием технологических сдвигов, связанных с инвестиционным процессом [1].

Цель исследования: провести оценку возможных объемов производства аграрной продукции на основе предлагаемой методики расчета структуры основных ресурсных затрат с использованием сведений таблиц использования товаров и услуг, входящих в систему национальных счетов и таблицы «Затраты-Выпуск». 
Методика исследования. Определение структуры затрат аграрного производства на основные производственные ресурсы, приводящей к росту выпуска продукции и повышению эффективности ресурсного потенциала, автор предлагает проводить с помощью метода построения производственной функции, который позволяет рассчитывать и прогнозировать целевые показатели в зависимости от разного уровня факторных признаков. Преимуществом предлагаемого метода является универсальность производственной функции при ее расчетах, в которых могут использоваться не только два факторных признака (как в классической функции Кобба-Дугласа), но и больше, в зависимости от установленных научных целей, от количества исследуемых факторных признаков, воздействующих на показатели выпуска продукции.

Для построения производственной функции большое значение имеет длина временного ряда, на основании которого проводится исследование. Чем больше временных периодов входит в расчет производственной функции, тем более достоверно ее параметры будут отражать складывающиеся тенденции и зависимости выпуска продукции от структуры ресурсоемкости аграрного производства. При этом необходимо учитывать, что полученные параметры производственной функции имеют три ограничения, т.к. характерны только: 1) для исследуемого временного периода, 2) для конкретного состава ресурсов, 3) в отношении отдельно взятой базы данных сведений о межотраслевых взаимодействиях. Соблюдение указанных условий зависит от поставленных исследовательских задач. Расчет параметров производственной функции для целей настоящей статьи проведен с использованием корреляционно-регрессионного анализа в программной среде Microsoft Excel.

Результаты исследования. С использованием данных международного исследовательского проекта World Input-Output Database (WIOD) на основе таблиц использования товаров и услуг, таблиц «Затраты-Выпуск» по странам мира [7] были проведены расчеты параметров производственной функции для аграрного производства России с учетом структуры и динамики ресурсоемкости продукции в 2000-2014 гг. Данный временной период является наиболее актуальным из существующих баз данных, позволяющих проводить исследования, для которых нуж- ны длинные динамические ряды, построенные по единой методике (15 лет и более). Для сравнения: аналогичная база данных Росстата за 2011-2017 гг. [6] хотя и содержит к настоящему моменту более актуальные сведения, тем не менее, охватывает только 7 лет, что недостаточно для целей эконометрики и может не в полной мере характеризовать динамику процессов в ресурсной сфере отраслевых комплексов. Использование международных статистических сведений было вызвано также необходимостью повышения достоверности получаемых результатов за счет снижения влияния инфляционных процессов, проведения межстрановых сопоставлений [3].

В результате расчетов была составлена трехфакторная производственная функция, в которой в качестве факторов выступают затраты в аграрной сфере на основные производственные ресурсы по группам затрат:

- затраты на продукцию машиностроения (в составе промежуточного потребления): машины и оборудование (в том числе сельхозтехника), компьютерная и электронная техника, электрооборудование, транспортные средства;

- затраты на топливно-энергетические ресурсы: уголь, нефтепродукты, электроэнергия, газ, тепловая энергия;

- затраты на химические продукты: удобрения, средства защиты растений.

Производственная функция аграрного производства России по структуре основных производственных ресурсов имеет следующий вид:

$$
\mathrm{P}=176,226 \cdot \mathrm{C}_{\mathbf{M}}^{0,078} \cdot \mathrm{C}_{\ni}^{0,179} \cdot \mathrm{C}_{\mathbf{X}}^{0,548}
$$

где $\mathrm{P}$ - валовая продукция сельского хозяйства, млн. долл.

$\mathrm{C}_{\mathrm{M}}$ - затраты на продукцию машиностроения, млн. долл.

$\mathrm{C}_{\ni}$ - затраты на топливно-энергетические ресурсы, млн. долл.

$\mathrm{C}_{\mathrm{X}}$ - затраты на химические продукты, млн. долл.

Числовые значения степени в формуле являются коэффициентами эластичности валовой продукции по соответствующим затратам. Параметры производственной функции за исследуемый период показывают, что наибольшее влияние на выпуск продукции оказывают инвестиции предприятий аграрного сектора в 
химические продукты. Прирост вложений в химические продукты на 1\% приводит к росту продукции на $0,548 \%$. Соответствующие параметры по продукции машиностроения и по топливноэнергетическим ресурсам равны 0,179\% и $0,078 \%$ соответственно.

Анализ ресурсоемкости производства аграрной продукции показывает, что аграрное производство России характеризуется низким уровнем использования удобрений и недостаточностью инвестиций в обновление материально-технической базы. В настоящее время происходит снижение показателей технического потенциала аграрного производства по большинству видов сельскохозяйственных машин. За период 2010-2019 гг. парк тракторов и зерноуборочных комбайнов в сельскохозяйственных организациях сократился в 1,5 раза, кормоуборочных комбайнов - в 1,7 раза, что привело к росту нагрузки на технику [5].

Принимаемые на государственном и региональном уровнях меры по повышению технической оснащенности (например, компенсация части стоимости техники производителю при ее реализации со скидкой предприятиям сельского хозяйства, льготный лизинг) позволяют компенсировать численное сокращение парка за счет приобретения более мощных и производительных машин. Интенсивность использования техники сопровождается тенденцией общего старения парка вследствие недостаточной степени обновления. В 2018 году доля техники, которая эксплуатируется более 10 лет, составила: по тракторам - 73,1\%, по зерноуборочным комбайнам - 61,5\%, по кормоуборочным комбайнам - 65,3\% [2]. Рост химизации аграрного производства в 2000-2019 гг. более чем в 3 раза положительно повлиял на урожайность сельскохозяйственных культур, однако еще не достигает уровня 1990 года.

Так как динамика затрат на химические продукты в исследуемом периоде оказывает наибольшее влияние на выпуск продукции аграрного производства, то прирост выпуска будет связан с повышением объема и доли вложений предприятий в использование продукции химической промышленности, а также с повышением объема инвестиций в технико-технологическую модернизацию производства, недостаток которых выступает ограничением для роста производства и повышения эффективности ре- сурсного потенциала в средне- и долгосрочной перспективе.

Рассчитанная формула производственной функции позволяет осуществить прогноз выпуска продукции аграрного производства в зависимости от изменения структуры и объема затрат на ресурсы, что приводит к изменению в структуре ресурсного потенциала. Изменение различных ресурсных параметров аграрного производства и выпуска продукции может быть реализовано по нескольким вариантам. В качестве первого базового варианта использованы фактические данные о структуре и объеме затрат на основные производственные ресурсы.

Вторая группа вариантов предполагает сохранение общих затрат на основные производственные ресурсы при повышении доли затрат на химические продукты. Это позволит выявить структуру затрат, которая обеспечит наибольший прирост продукции аграрного производства. Однако данный метод имеет ограничения его использования в практической деятельности, так как не учитывает реально сложившуюся технологию производства в природноклиматических условиях России. Повышение доли затрат на химические продукты при сохранении общих затрат приведет к сокращению вложений в технику и энергетические ресурсы, что может исказить реальные производственные результаты функционирования предприятий. Сокращение инвестиций в использование техники повлечет за собой усиление дисбаланса ресурсного потенциала, увеличение масштабов неиспользуемых ресурсов.

В качестве дополнительных вариантов расчета выпуска продукции аграрного производства автор предлагает использовать сложившуюся структуру затрат в странах, сопоставимых с Россией по уровню и структуре ресурсоемкости, как ориентир для определения возможных направлений изменения структуры затрат в целях повышения объемам выпуска продукции и роста эффективности использования ресурсного потенциала. Анализ ресурсоемкости производства аграрной продукции по странам мира позволил выявить несколько стран, схожих с Россией по уровню и структуре ресурсных затрат в аграрном производстве, а также, по природноклиматическим условиям, по масштабам сельского хозяйства, к ним относятся Германия, Канада, Польша, Нидерланды, США. 
Третья и четвертая группы вариантов прогноза выпуска продукции аграрного производства предполагают рост затрат на отдельные виды ресурсов при сохранении и увеличении затрат на другие ресурсы, что приведет не только к повышению объема выпуска продукции, но и к изменению уровня и структуры ресурсоемкости аграрного производства, к изменению структуры ресурсного потенциала. Целевой рост объема затрат, который приводит к изменению структуры затрат, исходит из необходимости повышения эффективности использования ресурсного потенциала с достижением в перспективе нормативных значений показателей ресурсного обеспечения. По техническим ресурсам необходимо увеличение ежегодных затрат на их покупку и обновление минимум в 2 раза, что позволит восполнять выбывающую технику и увеличивать существующий парк машин и оборудования. По энергетическим ресурсам, используемым, главным образом, при эксплуатации техники, рост составит 1,5 раза, что связано с повышением технического уровня техники и сокращением потребности в большем приросте использования топлива (табл. 1).

Анализ расчетов показывает, что прирост инвестиций в основные производственные ресурсы (особенно по химическим продуктам) приводит к соответствующему приросту продукции, как валовому, так и чистому. Наиболее реальными вариантами структуры ресурсного потенциала, обеспечивающими прирост выпуска продукции и повышение эффективности использования ресурсов, являются:

1) повышение объема вложений в химические продукты в 1,5 и в 2 раза при сохранении финансовых вложений в другие ресурсы, что приведет к повышению эффективности аграрного производства на $23,9 \%$ и $44,2 \%$ соответственно;

2) изменение структуры инвестиций в основные производственные ресурсы по соответствующей структуре в Нидерландах и США, где структура ресурсоемкости аграрного производства в наибольшей степени схожа с российскими показателями;
3) изменение структуры инвестиций в основные производственные ресурсы по соответствующей структуре в Германии, где структура и доля вложений в основные производственные ресурсы наиболее приближены к российским показателям.

Таким образом, для повышения эффективности использования ресурсного потенциала и прироста объемов аграрного производства необходимо одновременное повышение инвестиций в основные производственные ресурсы при изменении структуры ресурсоемкости производства аграрной продукции. Прирост производства будет связан, прежде всего, с ростом инвестиций в повышение уровня химизации аграрного производства, в обновление и модернизацию технического потенциала аграрной сферы.

Заключение. Одной из главных тенденций формирования и использования ресурсного потенциала аграрного производства является несоответствие структуры затрат предприятий на основные виды производственных ресурсов по сравнению с отдачей от их использования. Расчеты, выполненные с использованием метода построения производственной функции, выявили, что рост инвестиций в химизацию сельского хозяйства на 1\% вызывает соответствующий прирост продукции на 0,55\%, что выше, чем прирост от вложений в продукцию машиностроения и энергетические ресурсы. При этом доля затрат на химизацию в общих затратах на основные производственные ресурсы, формируемые вне агропродовольственного комплекса, составляет 16\%. [4] Представленный метод расчета зависимости производственных показателей от ресурсных затрат является основой для прогнозирования развития аграрного производства, и может быть применим и к другим сферам национальной экономики. Экономикоматематические расчеты влияния различных вариантов структуры ресурсных затрат на объемы получаемой продукции могут быть использованы для обоснования приоритетных направлений государственной аграрной политики в сфере ресурсного потенциала. 
Таблица 1. Выпуск продукции аграрного производства России в зависимости от изменения структуры и объема затрат на основные производственные ресурсы

\begin{tabular}{|c|c|c|c|c|c|c|c|c|}
\hline \multirow{2}{*}{$\begin{array}{c}\text { Варианты структуры } \\
\text { ресурсного потенци- } \\
\text { ала }\end{array}$} & \multicolumn{3}{|c|}{$\begin{array}{l}\text { Структура затрат на } \\
\text { основные производ- } \\
\text { ственные ресурсы,\% }\end{array}$} & \multicolumn{3}{|c|}{$\begin{array}{c}\text { Затраты на основные } \\
\text { производственные ре- } \\
\text { сурсы, млн. долл. }\end{array}$} & \multirow{2}{*}{$\begin{array}{c}\text { Выпуск продукции } \\
\text { аграрного произ- } \\
\text { водства, млн. долл. }\end{array}$} & \multirow{2}{*}{$\begin{array}{c}\text { Чистый } \\
\text { прирост } \\
\text { выпуска } \\
\text { продукции } \\
\text { (за минусом } \\
\text { прироста } \\
\text { затрат),\% } \\
\text { к базовому } \\
\text { варианту }\end{array}$} \\
\hline & $M^{*}$ & $\ni$ & $\mathrm{X}$ & M & $\ni$ & $\mathrm{X}$ & & \\
\hline І. Базовый & 26,5 & 57,9 & 15,6 & 4048 & 8853 & 2388 & 121698 & - \\
\hline \multicolumn{9}{|c|}{ ІІа. Изменение структуры затрат при сохранении объема затрат } \\
\hline $\begin{array}{l}\text { Рост доли затрат на } \\
\text { удобрения до } 20 \%\end{array}$ & 25,1 & 54,9 & 20,0 & 3837 & 8394 & 3058 & 137459 & 12,9 \\
\hline $\begin{array}{l}\text { Рост доли затрат на } \\
\text { удобрения до } 25 \%\end{array}$ & 23,6 & 51,4 & 25,0 & 3608 & 7859 & 3822 & 152781 & 25,5 \\
\hline \multicolumn{9}{|c|}{$\begin{array}{l}\text { IIб. Изменение структуры затрат при сохранении объема затрат (по структуре затрат } \\
\text { в странах с сопоставимым с Россией уровнем и структурой ресурсоемкости) }\end{array}$} \\
\hline Германия & 24,4 & 41,4 & 34,2 & 3730 & 6330 & 5229 & 174951 & 43,8 \\
\hline Нидерланды & 30,1 & 45,0 & 24,9 & 4602 & 6880 & 3807 & 151692 & 24,6 \\
\hline США & 12,7 & 57,6 & 29,7 & 1942 & 8806 & 4541 & 163321 & 34,2 \\
\hline \multicolumn{9}{|c|}{ III. Изменение структуры затрат с изменением объема затрат } \\
\hline $\begin{array}{l}\text { Рост объема затрат на } \\
\text { удобрения в } 1,5 \text { раза } \\
\text { при сохранении объе- } \\
\text { ма других затрат }\end{array}$ & 24,6 & 53,7 & 21,7 & 4048 & 8853 & 3582 & 151978 & 23,9 \\
\hline $\begin{array}{l}\text { Рост объема затрат } \\
\text { на удобрения в } 2 \text { раза } \\
\text { при сохранении объе- } \\
\text { ма других затрат }\end{array}$ & 22,9 & 50,1 & 27,0 & 4048 & 8853 & 4776 & 177929 & 44,2 \\
\hline $\begin{array}{l}\text { Целевой рост объема } \\
\text { затрат на удобрения } \\
\text { в } 1,6 \text { раза при росте } \\
\text { затрат на технику в } 2 \\
\text { раза и на энергети- } \\
\text { ческие ресурсы в 1,5 } \\
\text { раза }\end{array}$ & 32,1 & 52,7 & 15,2 & 8096 & 13280 & 3821 & 178696 & 38,7 \\
\hline \multicolumn{9}{|c|}{ IV. Изменение объема затрат при сохранении структуры затрат } \\
\hline $\begin{array}{l}\text { Рост объема всех } \\
\text { затрат в } 1,5 \text { раза }\end{array}$ & 26,5 & 57,9 & 15,6 & 6072 & 13280 & 3582 & 168670 & 32,3 \\
\hline $\begin{array}{l}\text { Рост объема всех } \\
\text { затрат в } 2 \text { раза }\end{array}$ & 26,5 & 57,9 & 15,6 & 8096 & 17706 & 4776 & 212626 & 62,2 \\
\hline
\end{tabular}

* М - продукция машиностроения; Э - топливно-энергетические ресурсы; X - химические продукты.

\section{Библиографический список}

1. Андрющенко С.А., Васильченко М.Я. Методология межотраслевого баланса в стратегическом управлении производственным потенциалом агропромышленного комплекса России // Аграрный научный журнал. 2015. № 8.- С. 68-74.

2. Национальный доклад о ходе и результатах реализации в 2018 году Государственной программы развития сельского хозяйства и регулирования рынков сельскохозяйственной продукции, сырья и продовольствия / Министерство сельского хозяйства Российской Федерации.-М., 2019.-180 с.- С. 92.

3. Потапов А.П. Оценка динамики затрат ресурсов и ресурсоемкости аграрного производства России // Аграрный научный журнал. 2018. № 5.- С. 85-91. 
4. Потапов А.П. Сбалансированность экономических механизмов роста эффективности использования ресурсного потенциала аграрного производства // Региональные агросистемы: экономика и социология.2019. - № 3. - C. 51-56. - URL: http://iagpran.ru/journal.php?tid=764.

5. Россия в цифрах. 2020: Крат. стат. сб. / Росстат. М., 2020. 550 с. - С. 359-361.

6. Федеральная служба государственной статистики - URL: https://www.gks.ru/accounts

7. National Input-Output Tables, Relaesed November 2016._- URL: http://www.wiod.org/new_site/database/niots. htm. 